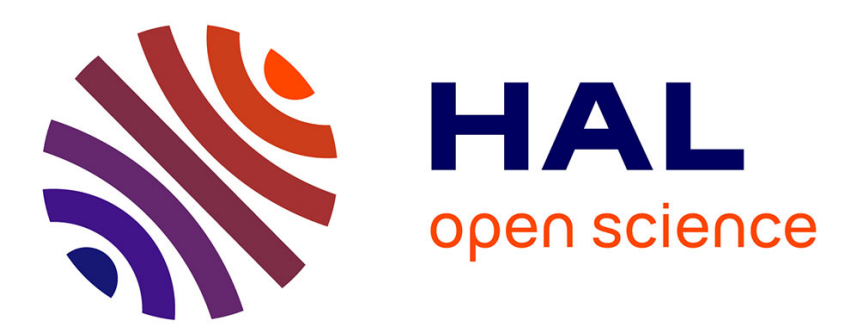

\title{
Response of Human Glioma U87 Xenografted on Mice to Non Thermal Plasma Treatment
}

Marc Vandamme, Eric Robert, Sébastien Dozias, Julien Sobilo, Stéphanie Lerondel, Alain Le Pape, Jean Michel Pouvesle

\section{- To cite this version:}

Marc Vandamme, Eric Robert, Sébastien Dozias, Julien Sobilo, Stéphanie Lerondel, et al.. Response of Human Glioma U87 Xenografted on Mice to Non Thermal Plasma Treatment. Plasma medicine, 2011, 1 (1), pp.27. hal-00683299

\section{HAL Id: hal-00683299 \\ https://hal.science/hal-00683299}

Submitted on 28 Mar 2012

HAL is a multi-disciplinary open access archive for the deposit and dissemination of scientific research documents, whether they are published or not. The documents may come from teaching and research institutions in France or abroad, or from public or private research centers.
L'archive ouverte pluridisciplinaire HAL, est destinée au dépôt et à la diffusion de documents scientifiques de niveau recherche, publiés ou non, émanant des établissements d'enseignement et de recherche français ou étrangers, des laboratoires publics ou privés. 


\title{
Response of Human Glioma U87 Xenografted on Mice to Non Thermal Plasma Treatment
}

\author{
Marc Vandamme, ${ }^{1,2,{ }^{*}}$ Eric Robert, ${ }^{1}$ Sébastien Dozias, ${ }^{1}$ Julien Sobilo, ${ }^{2}$ \\ Stéphanie Lerondel, ${ }^{2}$ Alain Le Pape, ${ }^{2}$ \& Jean-Michel Pouvesle ${ }^{1}$ \\ ${ }^{1}$ GREMI UMR-6606 CNRS, Université d'Orléans, ${ }^{2 T A A M-C I P A, ~ U P S 44 ~ C N R S ~}$ \\ *Address all correspondence to: Marc Vandamme, GREMI UMR-6606 CNRS, Université d'Orléans, 14 rue d'Issoudun, \\ BP 6744, 45067 Orleans cedex 2, France; Fax: 33 (0) 2 38.41.71.54; marc.vandamme@cnrs-orleans.fr
}

\begin{abstract}
Non thermal atmospheric plasma is a new promising candidate in anticancer therapy. We have already reported the absence of skin damage induced by our plasma treatment. Preliminary results suggested that this treatment could also induce an antitumor effect on U87 malignant glioma xenografts, and we conducted this work to evaluate the antitumor efficacy of plasma in this model. Antitumor effects were assessed by tumor volume measurement and bioluminescence imaging (BLI). Plasma treatment was applied during five consecutive days in open air with a $\mu$ s-duration pulsed floating electrode dielectric barrier discharge (FE-DBD), which delivered about $0.75 \mathrm{~W}$ at $200 \mathrm{~Hz}$ on the mouse skin. Our results showed a significant tumor volume decrease of $56 \%$ for treated mice at the end of the treatment, with a concomitant decrease of BLI intensity. Moreover, this tumor volume reduction translated into an increase of mouse life span of $60 \%$, median survival being 9.5 and 15.0 days for control and plasma-treated mice, respectively. In conclusion, our study demonstrates a marked antitumor effect of plasma treatment in U87 glioma xenografts. These results, obtained in both a radio and chemoresistant model, are very promising and highlight the potential of plasma treatment as an anticancer treatment with little or no toxic side effects.
\end{abstract}

KEY WORDS: cancer therapy, dielectric barrier discharge (DBD), non thermal plasma, glioma, xenograft model antitumor assay

\section{INTRODUCTION}

In Europe, estimated new cancer cases in 2006 were about 3.2 million and represented 1.7 millions of deaths. ${ }^{1}$ In many tumor types, survival has not significantly increased in the past decades, despite the emergence of new targeted chemotherapy. New treatment concepts or cytotoxic drugs are urgently needed to improve cancer patient outcome. In this context, we evaluated the interest of a local treatment with non thermal atmospheric pressure plasma as a new antitumor treatment. We choose to perform this evaluation on U87-MG, a high-grade glioma model, which is a representative model of brain tumor typically used for treatment efficacy screening. Malignant gliomas are the most common primitive human brain tumors and represent one of the most aggressive tumor types. ${ }^{2,3}$ Indeed, despite aggressive treatment including chemo- and radiotherapy, the median survival for patients of newly diagnosed malignant glioma is restricted to 8-15 months. ${ }^{2,3}$ 
Over the past few years, non thermal atmospheric pressure plasma has emerged as a novel promising tool in medicine. ${ }^{4}$ Non thermal plasma is a partially ionized gas, containing electrons, positive/negative ions, radicals, various excited molecules, energetic photons (UV), and generating transient electric field. Electrons present in non thermal plasma are highly energetic, with a typical temperature above $10,000 \mathrm{~K}$, while ions and neutral species remain at room temperature.

Numerous applications of plasma have been investigated, including sterilization and bacterial decontamination. ${ }^{5,6}$ Chemically reactive species and especially short-lived radicals such reactive oxygen species (ROS) are of major importance for bacterial decontamination. ${ }^{7}$ Atmospheric plasmas have also proved their efficacy in blood coagulation by catalyzing the natural blood coagulation processes. ${ }^{8}$ Moreover, treatment of biological tissue and cells has been investigated. Pioneer studies exploring plasma effects on cells have shown an instantaneous detachment of Chinese hamster ovarian (CHO-K1) cultured cells from the surface for low doses of plasma $(<0.2 \mathrm{~W})$, while higher doses induce severe damage and necrosis. ${ }^{9-11}$ Cell detachment after plasma treatment was also observed in other models. ${ }^{12,13}$

An induction of apoptosis on 3T3 mouse fibroblast was observed $24 \mathrm{hr}$ after plasma needle treatment, ${ }^{10}$ and induction of in vitro tumor cells death was reported by several authors. ${ }^{14,15}$ For example, Fridman et al. have shown an apoptosis induction of the melanoma cancer cell line with the use of an FE-DBD plasma. ${ }^{14} \mathrm{Kim}$ et al. have also reported that plasma treatments induce cell death in a melanoma cell line, and that this effect was potentiated by association of plasma with antibody-conjugated nanoparticles. ${ }^{15}$ DNA damages, cytoskeletal damages, membrane cell charging, and permeation have been proposed to participate in apoptosis induction. ${ }^{14,16}$ However, apoptotic processes involved remain rather unclear and need further investigations.

These encouraging results dealing with in vitro induction of apoptosis on different cell lines led us to explore effects of plasma treatment on xenograft tumor, the first in vivo approach on potential antitumor effect of non thermal treatment. Results of this treatment were unpredictable due to the fact that interaction between plasma and tumor cell might be quite different in in vitro and in vivo experiments. In particular, the presence of the skin and the use of a 3D tumor model might introduce crucial changes and modify the in vivo antitumor effects of plasma.

To develop plasma for in fine clinical applications, plasma tolerance and effects on organisms have to be determined. Fridman et al. have shown that plasma can be applied directly to a living tissue, and have determined the maximum tolerated dose of plasma DBD on mouse skin by histology analysis. ${ }^{8}$ We have previously shown the safety of our plasma treatment protocol for the whole mouse organism and the absence of skin damages of the treated zone. ${ }^{17}$ Moreover, an in vivo antitumor effect of plasma treatment was also observed in a small cohort of mice. ${ }^{17}$

The U87-MG glioma cell line was chosen to perform this in vivo antitumor efficacy study. This cell line is characterized by a high radio and chemoresistance, and is an adequate model to explore a significant antitumor effect. Moreover, heterotopically 
grafted, this cancer cell line presents a hemispherical growth that is a well-suited configuration for treatment with plasma and allows an accurate following of tumor growth by caliper measurement. This plasma treatment was performed in open air with a $\mu$ sduration pulsed FE-DBD that delivered less than $0.75 \mathrm{~W}$ on the mouse skin at $200 \mathrm{~Hz}$. In this configuration, discharge ignites when the powered electrode approaches the tumor surface at a distance of less than $\sim 3 \mathrm{~mm}$.

In this work, we first characterized the plasma generated by the developed FE-DBD system through electrical measurements. Plasma homogeneity during tumor treatment was analyzed with an ICCD camera. Then, we investigate whether five consecutive days of plasma treatment during 6 min per day induced an antitumor effect on U87 gliomabearing mice by tumor volume measurement and bioluminescence imaging.

\section{MATERIAL AND METHODS}

\section{A. Experimental Setup}

For all experiments, we used a dielectric barrier discharge (DBD) plasma. Figure 1 presents the whole experimental equipment, and Figure 2 represents the DBD power supply schematic.

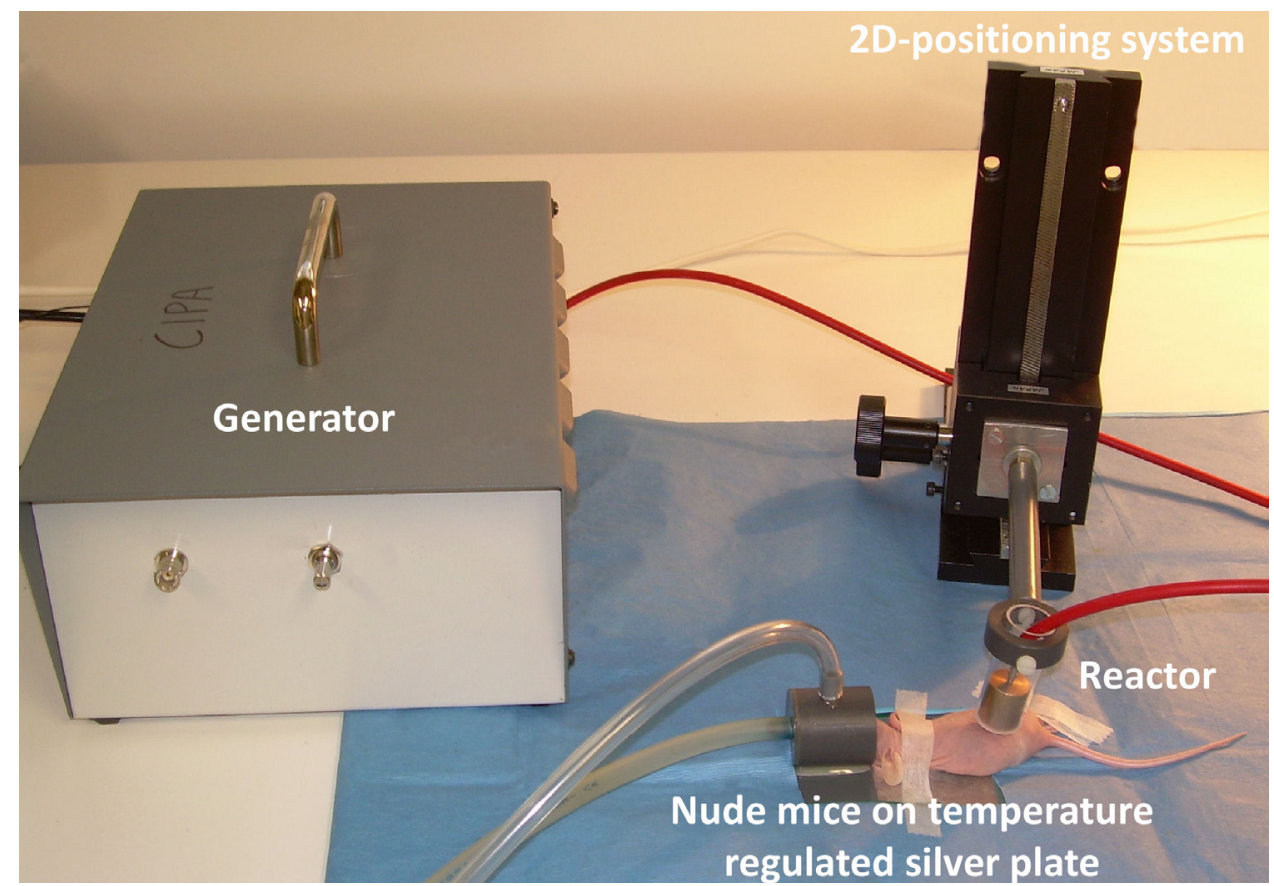

FIGURE 1. Picture representing the whole experimental equipment used to produce DBD plasma. To perform plasma treatment, mice were placed on a temperature-regulated silver plate. 


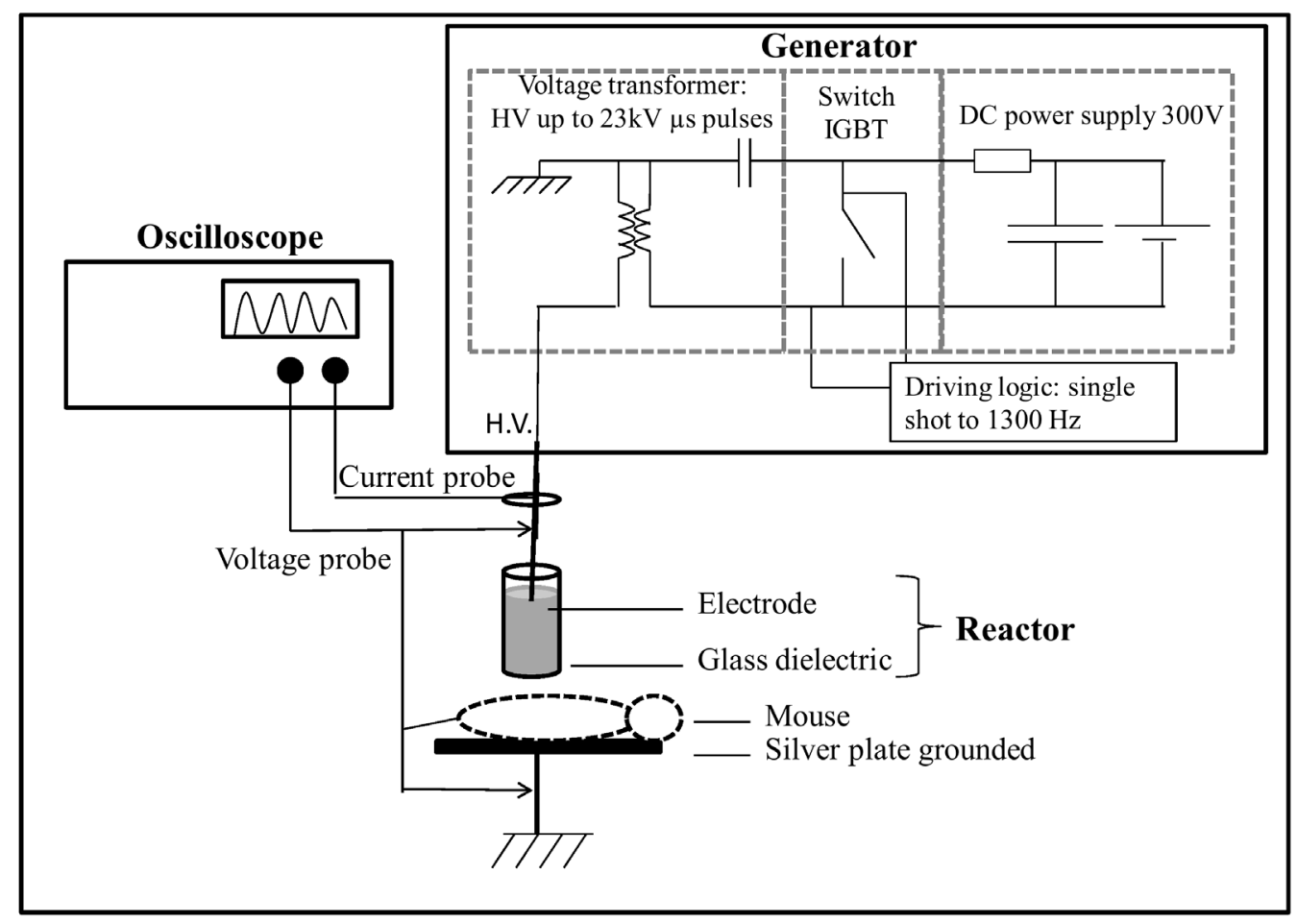

FIGURE 2. Schematics of the DBD setup and of the pulsed power supply.

The electrical driver articulates around three main subassemblies, namely, a DC power supply, a solid state switch, and a voltage pulse transformer. The $300 \mathrm{~V}$ amplitude DC power supply is used to store energy in a $700 \mathrm{nF}$ capacitor. The fast discharge of this capacitor is triggered at a variable repetition rate through an IGBT switch in the primary coil of a transformer that allows to produce a voltage pulse amplitude reaching up to $23 \mathrm{kV}$ in the present setup. The high-voltage (HV) pulse is applied on an $\mathrm{HV}$ voltage electrode consisting of a $10 \mathrm{~mm}$ high, $17 \mathrm{~mm}$ diameter aluminium cylinder. This $\mathrm{HV}$ electrode is inserted inside a $1 \mathrm{~mm}$ thick, $60 \mathrm{~mm}$ high, and $19 \mathrm{~mm}$ outer diameter borosilicate glass tube. The bottom base of this glass tube is glued with a $1 \mathrm{~mm}$ thick borosilicate disk, $19 \mathrm{~mm}$ in diameter, which acts as the dielectric wall of the DBD reactor. This system generates air plasma from the external surface of the dielectric barrier disk and a living organism that is placed on a ground plate electrode. This DBD system can produce discharges with frequency that can vary from a single shot to $1300 \mathrm{~Hz}$. The energy stored in the DC powered capacitor multiplied by the generator repetition rate provides the maximum available power.

For a pulse repetition rate of $200 \mathrm{~Hz}$, the maximum power available is $\sim 6.3 \mathrm{~W}$, leading to a maximum power density of $2.7 \mathrm{~W} / \mathrm{cm}^{2}$, when considering a uniform distribution of the discharge over the $2.3 \mathrm{~cm}^{2}$ surface of the glass disk. This rough estimate indicates 
the maximum mean power density, since it neither accounts for the random filamentary nature of the DBD discharge nor for the power losses associated with the impedance mismatching between the driver output and the DBD reactor. For all tests discussed in this paper, non thermal plasmas were generated in ambient air at atmospheric pressure.

\section{B. Diagnostics}

A HV probe (Tektronix P6015A, $75 \mathrm{MHz}$ bandwidth) and a current probe (Tektronix TCP202, $50 \mathrm{MHz}$ bandwidth) were used to characterize the voltage and current waveforms delivered across the DBD reactor. Both probes were connected to an oscilloscope (Tektronix TDS510A).

Discharge homogeneity was analyzed with the use of an ICCD camera (PI-Max, Princeton Instruments) equipped with a $60 \mathrm{~mm}$ lens. Experiments were performed both in single-shot or multishot acquisition mode on few discharges, and by image accumulation over a few thousands of discharges, this latter measurement being much more representative of the mouse plasma treatment.

\section{Animals and Tumors}

Female athymic NCr/Sed nude (nu/nu) mice, five to six weeks of age, were purchased from Charles River (St. Germain sur l'Arbresle, France) and housed for one week before experimentation. For all experiments, animals were housed in plastic cages inside a controlled ventilated rack and had access to food and water ad libitum. Animal procedures were performed according to institutional and national guidelines (EC directive 86/609/ CEE, French decree No. 87-848). Tumor grafts, plasma irradiation, and bioluminescence imaging were carried out under general gaseous anesthesia obtained with $3 \%$ isoflurane (Aerrane, Baxter, Deerfield, Connecticut) in air.

Tumor xenografts were originally obtained by subcutaneous injection of a suspension of U87-Luc human malignant glioma cells $\left(10^{6}\right.$ cells in $\left.0.1 \mathrm{~mL} 0.9 \% \mathrm{NaCl}\right)$ into the hind legs of mice. This cell line purchased from Caliper is stably transfected with firefly luciferase gene. U87 xenografts were then maintained in vivo by sequential passages of tumor fragments in nude mice grafted in the inguinal pit.

\section{Treatment Procedures}

Treatment started when tumors reached a volume of $150 \pm 50 \mathrm{~mm}^{3}\left(D_{0}\right)$. Mice were randomly assigned into two groups. In the control group, mice were not treated. In the plasma group, mice received plasma treatment for five consecutive days. Tumor treatments on mice were performed at $200 \mathrm{~Hz}$ in open air each day during 6 min (three periods of 2 min separated by $1 \mathrm{~min}$ ). To perform plasma treatment, anesthetized mice were placed on a humidified, temperature-regulated silver plate, and the plasma reactor was positioned at a distance of $2 \mathrm{~mm}$ from the tumor (Fig. 1). These treatment parameters and procedure ensure reproducibility of plasma treatment and limit side effects on mice. 


\section{E. Antitumor Effect of Plasma Treatment}

To follow tumor growth, tumor volume was determined every day with the international current standard technique for tumor volume measurement. ${ }^{18,19}$ Two perpendicular diameters were measured with a caliper. Tumor volume ( $\mathrm{V}$ in cubic millimeters) was calculated as $V=\left(\right.$ length $\times$ width $\left.{ }^{2}\right) / 2 .{ }^{18,19}$ Mice were anesthetized and killed by cervical dislocation when a tumor reached $1000 \mathrm{~mm}^{3}$, thus defining the "survival times." The percentage of increase in the life span was calculated as $(T-C) / C \times 100$, where $T$ and $C$ are the survival times of the treated and control animals.

Tumor response to plasma treatment was also assessed by BLI before $D_{0}$ and $48 \mathrm{hr}$ after treatment completion $\left(D_{6}\right)$. Bioluminescence allows the evaluation of very early stages of antitumor effect prior to physical reduction of tumor volume since bioluminescence intensity is closely dependant on tumor activity. ${ }^{20}$ Mice were intraperitoneally injected with $2 \mathrm{mg}$ beetle luciferin (potassium salt, Promega) and were then anesthetized. Ten minutes later, bioluminescence imagings were carried out using an ORCA II BT C4742-98-26 LW (Hamamatsu Photonics, Massy, France). Data acquisition was achieved using HiPic software (Hamamatsu Photonics). Merging of bioluminescence images and regions of interest quantification were obtained using ImageJ software (http://rsb.info.nih.gov/ij/index.html).

\section{F. Statistical Analysis}

Unless otherwise noted, data were reported as mean \pm SEM (standard error of the mean). Statistical analysis was performed using GraphPad 5.0 software (GraphPad Prism 5.0 Software MacKiev GraphPad Software, Inc. 1994-2005). For each parameter analyzed, treated and nontreated tumors were compared using the nonparametric Mann-Whitney $U$ test. Kaplan-Meier curve analysis was performed using the log-rank test. Differences were considered significant at $p$ values $<0.05$.

\section{RESULTS}

\section{A. Plasma Characterization}

Figure 3 presents the voltage and discharge current signals measured for a $200 \mathrm{~Hz}$ repetition rate operation. The voltage waveform exhibits a $4.5 \mu$ s rising front up to a $23 \mathrm{kV}$ amplitude, and a damped oscillation vanishing over about $25 \mu \mathrm{s}$. This voltage waveform was measured to be constant whatever the pulse repetition rate is up to $1300 \mathrm{~Hz}$, and also for gap thicknesses ranging from $0.5 \mathrm{~mm}$ to a few millimeters; this latter condition corresponding to the absence of the DBD plasma associated with streamer formation across the air gap. The current probe, surrounding the cable connected to the HV electrode, measures the total current, which is the sum of the displacement current across the dielectric barrier and the actual discharge current flowing across the air plasma. The discharge current presented in Figure 3 is thus inferred from the probe measurement 


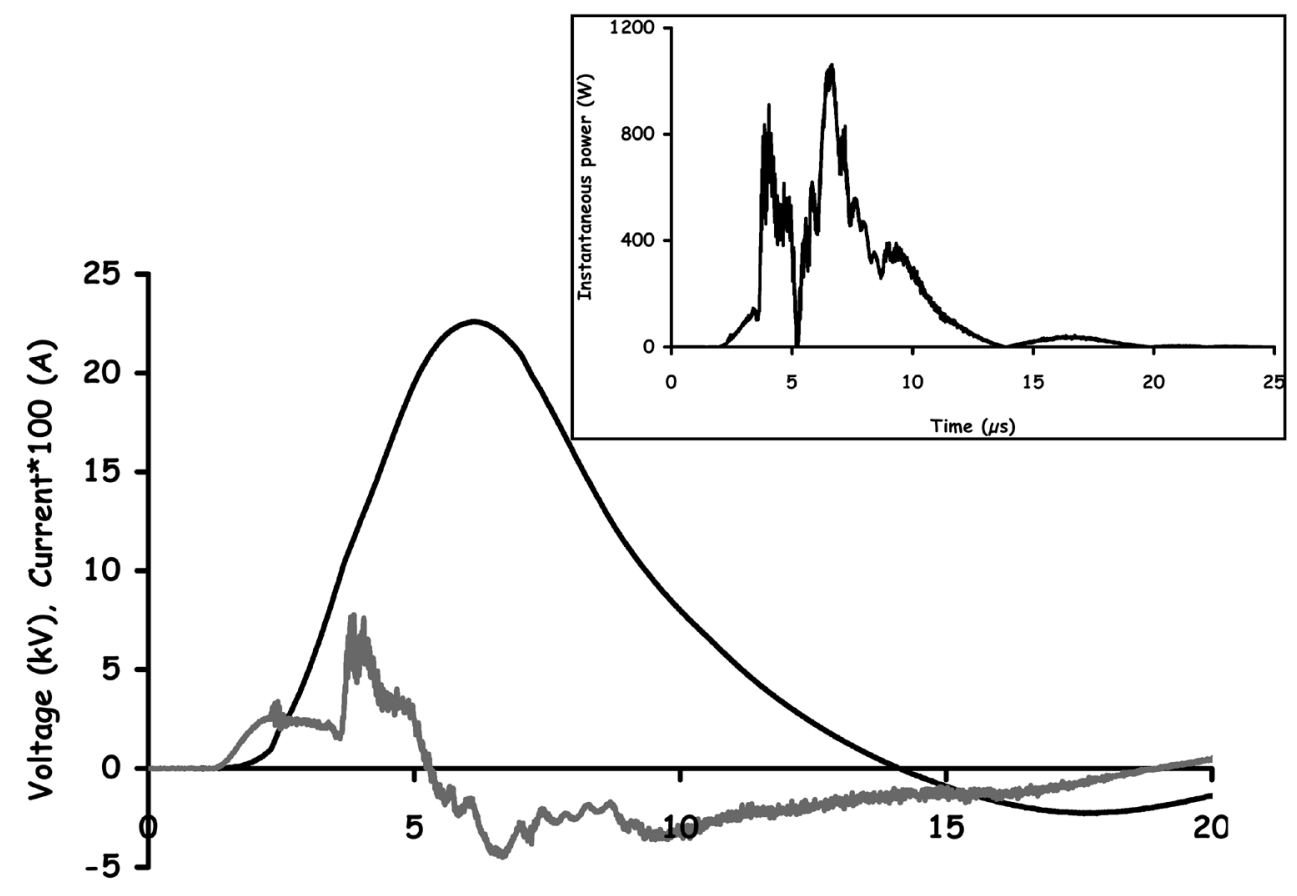

Time ( $\mu s)$

FIGURE 3. Voltage (dark line) and current (gray line) measured during a treatment with the discharge repetition rate at $200 \mathrm{~Hz}$.

by subtracting to the total current waveform, the displacement current signal measured when no plasma is produced, which is for an air gap larger than $5 \mathrm{~mm}$ in our experimental conditions. This method for actual plasma discharge current measurement was inspired by the results published by Lu and Laroussi. ${ }^{21}$ With the relatively slow rise time of the voltage pulse delivered by our electronic driver, the discharge current consists of a superposition of current spikes having duration of a few nanoseconds; the limited bandwidth of the probe used in this work results in the temporal integration of these spikes, which are measured as 20 ns long current pulses. Time-resolved ICCD imaging experiments, not presented in this paper, have shown that streamer production in the air gap is observed during about $20 \mu$ s after the current signal onset. The insert in Figure 3 presents the evolution of the instantaneous power delivered across the plasma during the whole voltage pulse application. Peak power reaches about $1 \mathrm{~kW}$ while the whole temporal integration of the power signal indicates that, for a $200 \mathrm{~Hz}$ repetition rate, $0.75 \mathrm{~W}$ are coupled to the DBD plasma. This corresponds to a maximum power density applied on the mouse skin of $0.33 \mathrm{~W} / \mathrm{cm}^{2}$. This value is below that required for a safe treatment without any significant damage on the skin for a three times 2 min exposure. ${ }^{17}$ 
Figure 4 presents two ICCD images recorded during application of the air plasma on the mouse skin at a $200 \mathrm{~Hz}$ repetition rate and for a gap of about $2 \mathrm{~mm}$. Figure 4A and the corresponding radial profile Figure $4 \mathrm{C}$ are obtained for a 10-discharge averaging, while Figures 4B and 4D correspond to an average over 5000 discharge events. The radial profiles, extracted from the ICCD images, are averaged along the vertical axis over a distance of $0.5 \mathrm{~mm}$ above the mouse skin, and correspond to the same space location. Each profile was then normalized to allow for a more straightforward comparison of their radial shape along the $14 \mathrm{~mm}$ wide zone, corresponding to the visible light air plasma emission region observed by the ICCD camera, in the horizontal axis direction. Both for 10 and 5000 discharge accumulations, the images and the corresponding profiles exhibit some rather flat background intensity level over which narrow and intense channels superimpose. Nevertheless, the calculations performed from the image profiles indicate that a significant reduction of about $40 \%$ of the standard deviation of the mean intensity value, from pixel position 50 to pixel position 200 in Figures 4C and 4D, is achieved for the 5000-accumulation recording in comparison with the 10-discharge averaging measurement. It must be remembered that plasma treatment of tumor is performed during $6 \mathrm{~min}$ at $200 \mathrm{~Hz}$, thus involving the accumulation of 72000 discharges. The mouse's breathing and the accumulation of such a large number of discharge result in the averaging of the gap thickness and the homogenization of the plasma action over the mouse skin.
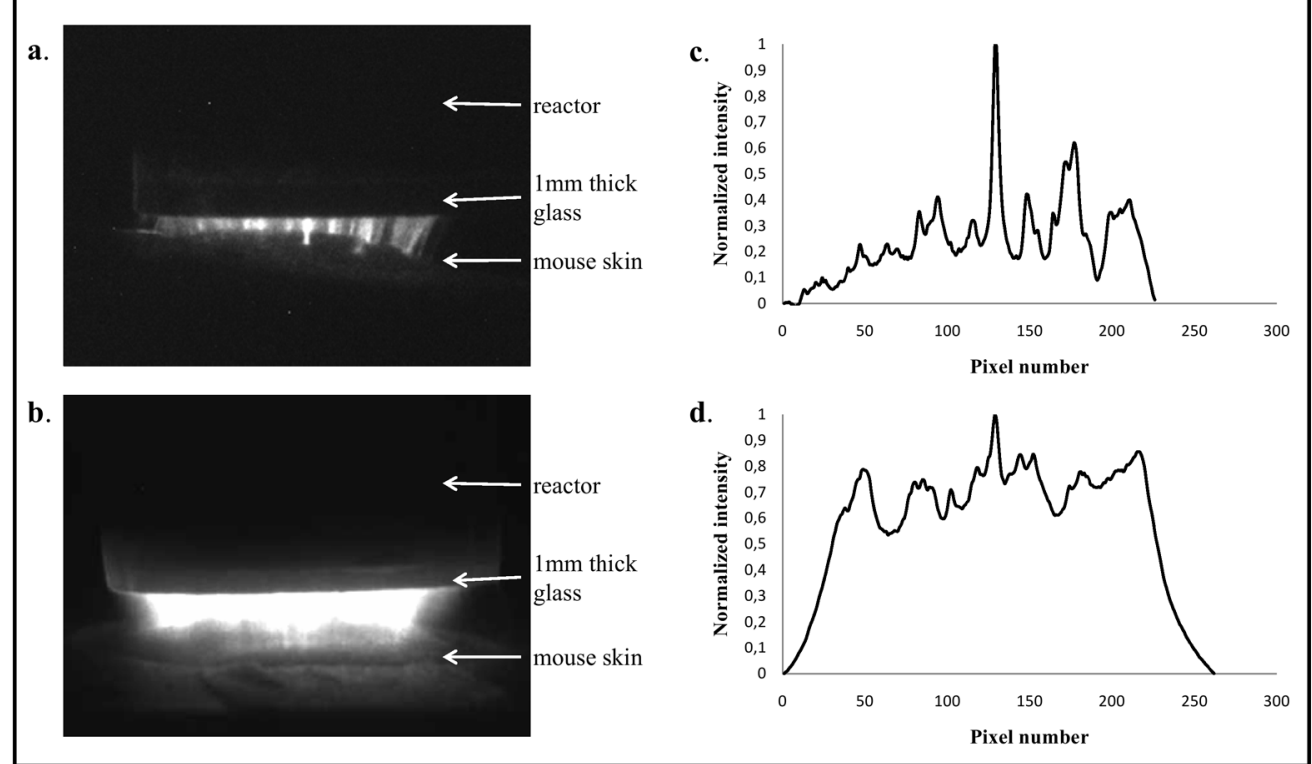

FIGURE 4. ICCD images recorded during application of the air plasma on the mouse skin at a $200 \mathrm{~Hz}$ repetition rate and for a gap of about $2 \mathrm{~mm}$. Image in (A) and the corresponding radial profile $(C)$ are obtained for a 10-discharge averaging, while $(B)$ and (D) correspond to an average over 5000 discharge events. 


\section{B. Plasma Induces Short-Term Antitumor Effects}

To explore the antitumor effect of plasma, treatment was applied every day for five consecutive days. We explored plasma treatment efficacy by tumor volume determination and by bioluminescence assay.

We first evaluated plasma antitumor activity after plasma treatment completion. To this end, treatment started when tumors reached a volume of $150 \pm 50 \mathrm{~mm}^{3}$, corresponding to $D_{0}$. Mice were randomly assigned into two groups, namely, the control (CTRL) and plasma (PLASMA) groups. Tumor volume was measured at day six $\left(D_{6}\right)$, corresponding to $48 \mathrm{hr}$ after the last plasma treatment. As shown in Figure 5, at the beginning of treatment, mean tumor volumes of CTRL and PLASMA groups were similar ( $p=$ 1.0). At $D_{6}$, mean tumor volume was $585 \pm 101 \mathrm{~mm}^{3}$ in CTRL group, whereas the mean volume of plasma-treated tumors only reached $259 \pm 45 \mathrm{~mm}^{3}$. This significant reduction of tumor growth $(\sim 56 \%, p=0.03)$ showed a marked plasma antitumor effect as early as the end of our treatment protocol (Fig. 6). However, tumor volume determination by caliper reflects total tumor tissue mass including areas of necrosis and edema, and so does not necessarily assess the effect of a treatment on the number of viable tumor cells.

Therefore, bioluminescence imagings were performed at $D_{0}$ and $D_{6}$. Figure 7 represents the ratio $D_{6} / D_{0}$ of BLI intensity, corresponding to the evolution of tumor activity between the beginning and the end of the treatment. As expected, plasma treatment induced a lower increase of BLI ratio than the increase obtained in the CTRL group. Indeed, in the CTRL group, we observed a 24-fold BLI intensity increase during the

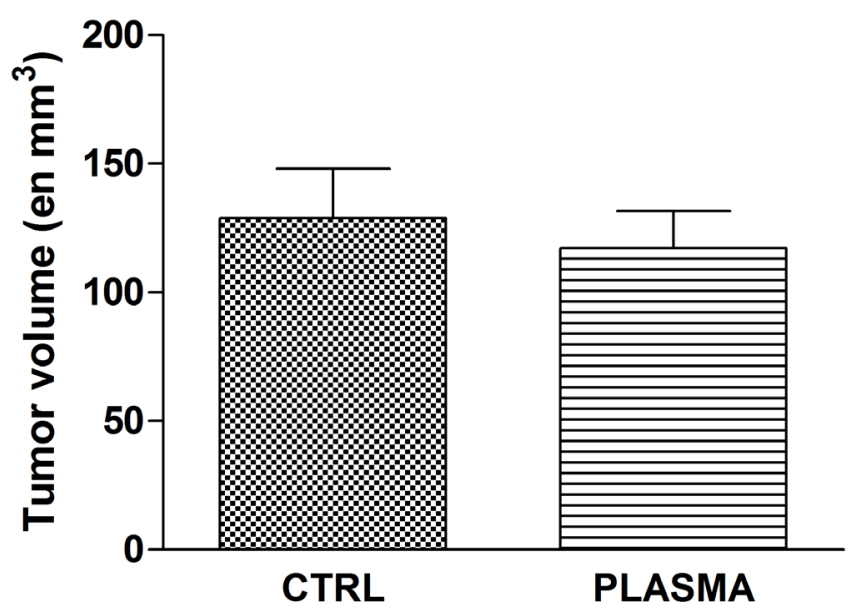

FIGURE 5. Tumor volume at the beginning of plasma treatment. Tumor volumes were measured with a caliper at the beginning of plasma treatment $\left(D_{0}\right)$. The column represents the mean ( \pm SEM) of tumor volume. ${ }^{*} p<0.05, n=8$ for each group. 


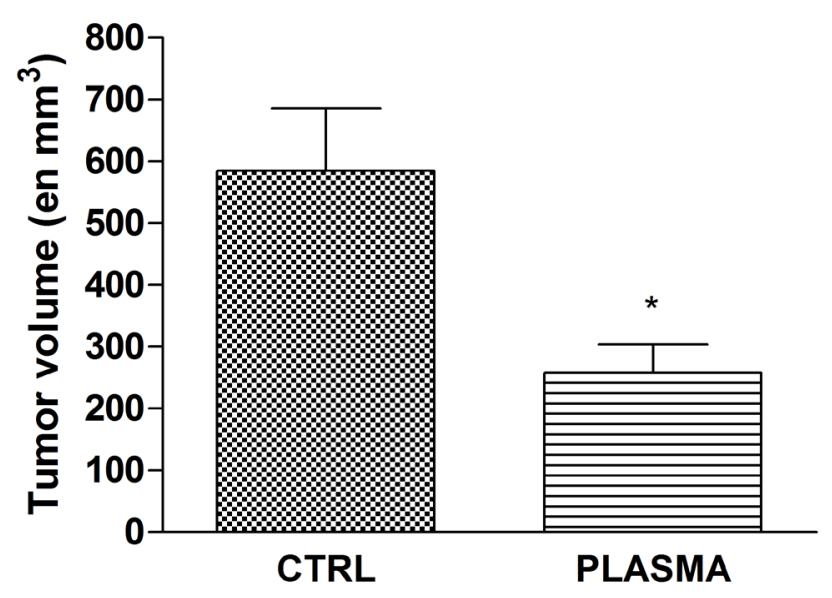

FIGURE 6. Effect of five consecutive plasma treatments on tumor volume. Plasma was administered when tumor reached $150 \pm 50 \mathrm{~mm}^{3}$ and consisted of five daily fractions (6 $\mathrm{min}, 200 \mathrm{~Hz}$ ). Tumor volumes were measured with a caliper on the sixth day. The column represents the mean ( \pm SEM) of tumor volume. ${ }^{*} p<0.05, n=8$ for each group.

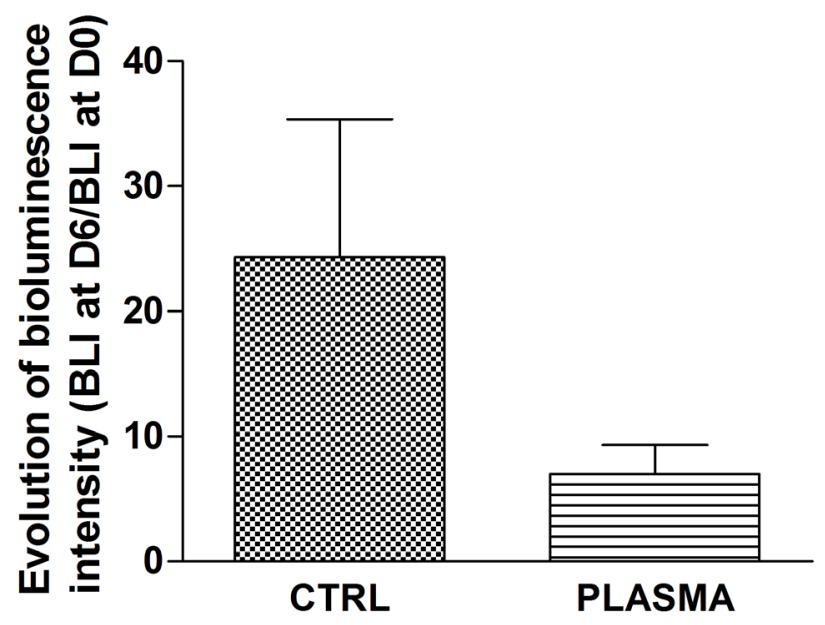

FIGURE 7. Tumor bioluminescence intensity at the end of plasma treatment. Plasma was administered when tumor reached $150 \pm 50 \mathrm{~mm}^{3}$ and consisted of five daily fractions ( $6 \mathrm{~min}, 200 \mathrm{~Hz}$ ). In vivo bioluminescence imaging were performed before and then $24 \mathrm{~h}$ after five consecutive days of treatments. Columns represent the mean ( \pm SEM) of tumor bioluminescence intensity at day six normalized to tumor bioluminescence intensity before treatment. $n=8$ for each group. 
treatment period, while in the PLASMA group, BLI intensity only increased sevenfold during the same treatment course. This reduction of BLI ratio $(\sim 70 \%)$ is consistent with the effect of plasma treatment on tumor volume at $D_{6}$ described above.

\section{Plasma Induces Long-Term Antitumor Effects}

To evaluate long-term treatment effects, tumor growth was followed every day until the tumors reached $1000 \mathrm{~mm} 3$ (Fig. 8). In the CTRL group, tumors grew exponentially and the mean time to reach $1000 \mathrm{~mm}^{3}$ was $9.6 \pm 0.9$ days. Plasma treatment was administered for five consecutive days from $D_{0}$ to $D_{4}$. During the treatment course, tumors did not significantly grow, mean tumor volume remaining stable between $D_{0}$ and $D_{4}$ (Fig. 8). After treatment completion, we observed a raise of tumor growth in plasma-treated mice, but tumor growth seemed less rapid than in the CTRL group. The mean time to reach $1000 \mathrm{~mm}^{3}$ was $15.0 \pm 0.8$ days. Tumor growth delay, corresponding to the difference of times needed to reach $1000 \mathrm{~mm}^{3}$ between CTRL and PLASMA groups, was 5.4 days for plasma-treated tumors, illustrating a significant antitumor effect of plasma. Moreover, we have included in our study a few mice bearing two xenografts (in each inguinal pit), the first one receiving plasma treatment, and the second one being used as a control, to determine whether plasma effects are localized. We have observed that kinetic growths of CTRL and plasma-treated tumors were similar to those of mice bearing only one tumor, highlighting a plasma effect limited to the treated zone.

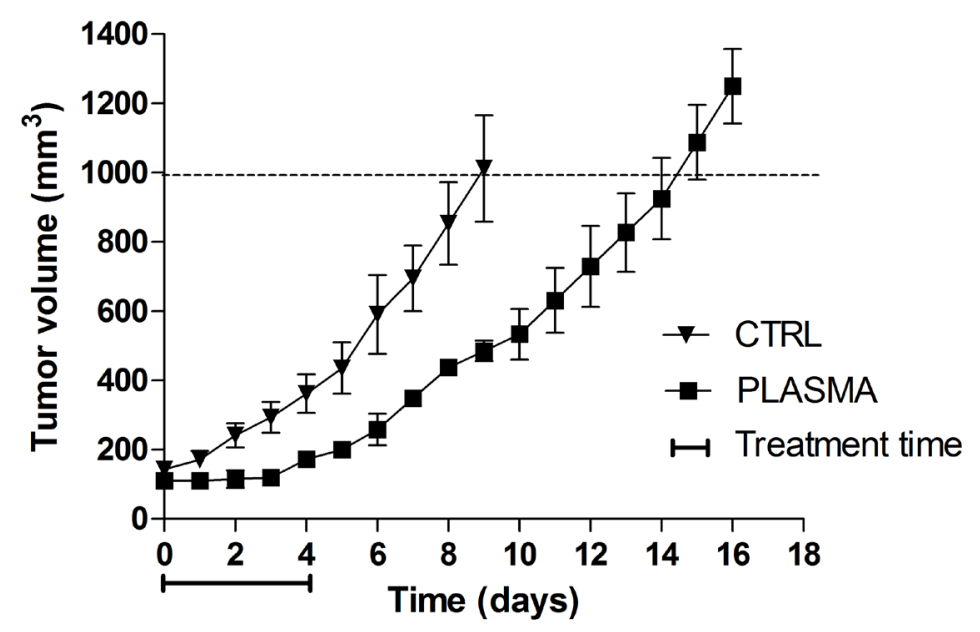

FIGURE 8. In vivo antitumor efficacy of plasma treatment. Plasma was administered when tumor reached $150 \pm 50 \mathrm{~mm}^{3}$ and consisted of five daily fractions (6 min, $200 \mathrm{~Hz}$ ). Tumor volumes were measured every day with a caliper until tumor reached a volume of $1000 \mathrm{~mm}^{3}$. Each point represents the mean ( \pm SEM) of tumor volume. $n=8$ for each group. 
The plasma effect was also evaluated using Kaplan-Meier curve analysis (Fig. 9), considering the percentage of tumor not having reached $1000 \mathrm{~mm}^{3}$ as the survival endpoint. Median survival was 9.5 days in the CTRL group. When mice received plasma treatment, the survival curve clearly shifted to the right, and the median survival was 15.0 days in the PLASMA group (versus CTRL $p=0.002$ ). This translates into an increase of life span of mice of $\sim 58 \%$.

\section{DISCUSSION}

Non thermal atmospheric plasma has emerged as a novel, promising tool in medicine. Indeed, the existence of various components in plasma such as electric field, UV radiation, uncharged species, electrons, and ions, which could interact with the treated tissue, makes plasma a good candidate for cancer treatment. Our preliminary data showed the safety of plasma treatment for the whole mouse organism and the absence of skin damages with our treatment parameters. ${ }^{17}$ An antitumor effect of plasma treatment was also observed using a small cohort of mice. ${ }^{17}$ To confirm these promising results, we performed this study on a larger number of U87-bearing mice.

In our experiments, we treated mice during five consecutive days for 6 min each day at $200 \mathrm{~Hz}$. This treatment protocol did not show any life-threatening effects on mice. We

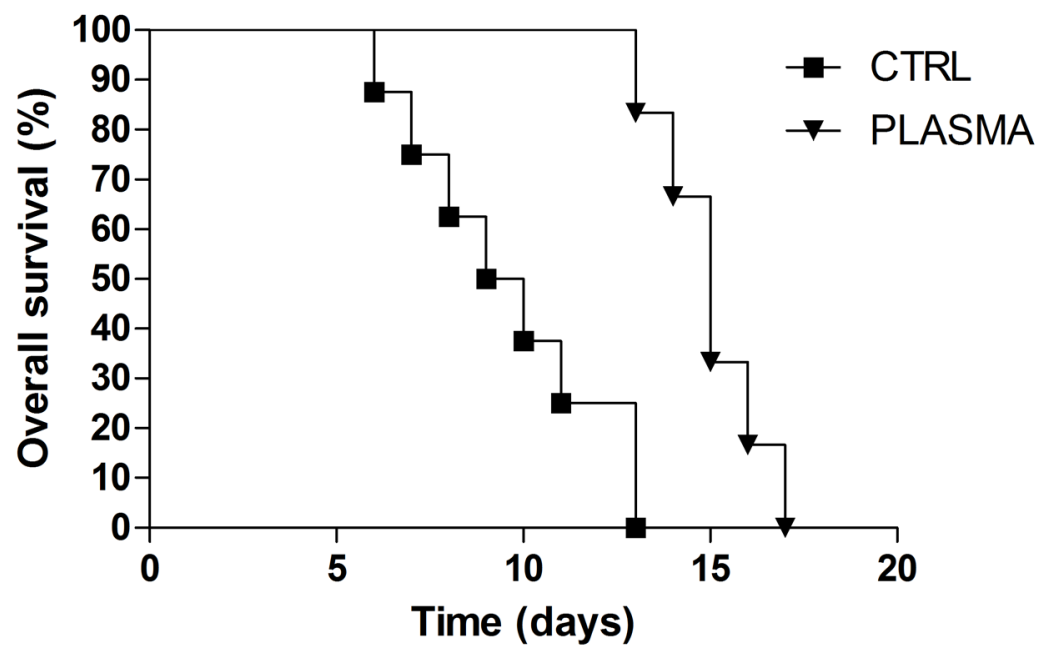

FIGURE 9. Response of subcutaneous glioma xenografts to plasma antitumoral treatments. When tumor reached $150 \pm 50 \mathrm{~mm}^{3}$, mice were randomly assigned into two groups, namely, CTRL and PLASMA, eight mice per group. Plasma treatments were delivered for five consecutive days $(6 \mathrm{~min}, 200 \mathrm{~Hz}$ ). Results are expressed as KaplanMeier plots, considering the percentage of tumor not having reached $1000 \mathrm{~mm}^{3}$ as the survival endpoint. 
evaluated plasma discharge homogeneity during mice treatment with an ICCD camera. It has been shown that the accumulation of a few thousands of discharges result in a significant homogenization of the plasma treatment over the mouse skin, while singleshot or a reduced number of discharge event operations would result in a very inhomogeneous skin surface treatment, inherent with the microsecond-duration DBD plasma including very narrow streamer channels. One promising issue to achieve a much higher spatial homogeneity, which may be required if the plasma treatment is fractioned in a great number of short duration exposures, each involving a reduced number of discharge accumulation, being to develop nanosecond DBD plasmas. ${ }^{22}$

In this study, we chose to evaluate the potential antitumor effect of plasma on U87 high-grade glioma. Malignant brain tumors remain a therapeutic challenge, i.e., despite aggressive surgery, radiotherapy, and chemotherapy, prognosis of patients with highgrade glioma remains poor and their life expectancy is reduced to few months. ${ }^{2,3}$ In the U87 model, our plasma treatment showed a significant reduction of tumor volume $(\sim 56 \%)$ at the end of the treatment period, as compared to nontreated mice. This result was confirmed by BLI imaging, which exhibited a lower increase of BLI intensity for treated tumor as compared to CTRL, with a reduction of BLI ratio of $\sim 70 \%$. This demonstrates an important effect of plasma on tumor activity, since BLI represents a gene expression closely dependent on proliferation and metabolism of all tumor cells. This result also showed that plasma treatment on a tumor of $200-300 \mathrm{~mm}^{3}$ (corresponding to a tumor length of $\sim 10-11 \mathrm{~mm}$ and thickness of $\sim 7-8 \mathrm{~mm}$ ) induces an effect on the majority of tumor cells, reflecting a high penetration depth of plasma effect. All of these illustrate a marked plasma antitumor effect as early as five days after treatment onset. To the best of our knowledge, plasma has already shown an antitumor activity, but only in in vitro experiments. Here, we described an in vivo antitumor activity of plasma, which is in accordance with previously published data reporting an apoptosis induction on the CHO cell line and the melanoma cancer cell line. ${ }^{10,14,15}$

Several reports have demonstrated the high resistance of U87-bearing mice to the cytotoxic effect of radiation therapy. The tumor control dose $50 \%$ or $\mathrm{TCD}_{50}$ (the radiation dose necessary to locally control $50 \%$ of the tumor) of U87 malignant glioma in vivo was as high as 75.2 Gy for single-dose radiotherapy treatment, ${ }^{23,24}$ and this $\mathrm{TCD}_{50}$ was even higher when radiation treatment was daily fractionated and applied at low dose (2 Gy per day). ${ }^{25}$ This treatment schedule of 2 Gy per day during two weeks has been reported to produce an increase in life span of about $200 \%$ in U87-bearing mice. ${ }^{26}$ In our study, plasma showed an increase of $60 \%$ of mice life span, which reflects a high cytotoxic effect of plasma treatment. Even if this increase in life span was smaller for plasma treatment than for radiotherapy, our treatment was applied during only five consecutive days at three times $2 \mathrm{~min}$ at $200 \mathrm{~Hz}$. Given the very good tolerability of plasma, frequencies and treatment protocol duration could be increased to improve plasma efficacy. Indeed, we observed a stabilization of tumor volumes during treatment course, suggesting that a more prolonged treatment should be of valuable interest.

The high cytotoxic effect observed in this study could be mediated by several com- 
ponents of plasma and involved different mechanisms. We have previously shown an increase of BLI intensity after the first day of plasma treatment, ${ }^{17}$ reflecting a possible tumor reoxygenation. This increase of oxygen supply and tumor reoxygenation could be linked to tumor temperature increase ${ }^{27}$ and the diffusion through the skin of $\mathrm{NO}$, a potent vasodilatator. ${ }^{28,29}$ This tumor reoxygenation generally observed after radiotherapy induced a tumor cell sensitization to chemo-/radiotherapy, and such an effect could be transposed in our case ${ }^{30}$ Moreover, the authors have demonstrated a cytotoxic effect of UV-C radiation on in vitro U87 cell lines. ${ }^{31}$ However, UV-C penetration through the skin was limited $(2 \mu \mathrm{m}),{ }^{32}$ and cannot reach the subcutaneous tumor in our model considering mouse skin thickness. Furthermore, electric fields are an important component of plasma and have also shown to induce an antitumor effect on U87 in vivo xenografts. This new antitumor strategy is currently evaluated in clinical trial for patients with recurrent glioblastoma. ${ }^{33,34}$ The presence of nanosecond electric pulse in plasma could induce an arrest of cell proliferation and contribute to the observed antitumor effect.

All these parameters (i.e., species, temperature, electric fields, etc.) could be toxic to cells, inducing membrane damages and changes in intracellular signaling pathways, finally leading to cell death. It is rather probable that, as observed for radiotherapy, efficacy of plasma treatment was tumor cell type dependent, and different parameters could be implicated in this effect as tumor hypoxia, cell cycle phase, and DNA repair capacities. ${ }^{35,36}$ Specific plasma can be created to produce either neutrals or charged particles: in particular, with the adjunction of gas mixtures such air/argon to raise up long-lived $\left(\mathrm{O}_{3}, \mathrm{NO}\right)$ and short-lived $(\mathrm{OH}, \mathrm{O})$ particles. This will help us to elucidate the critical mechanism(s) involved in plasma cytotoxic effects and thereafter to increase plasma treatment efficacy.

In the future, to improve plasma antitumor efficacy, it should be kept in mind that plasma treatment presents a broad range of effects. In particular, it has been shown that cells become transiently permeable during plasma exposure. ${ }^{37,38}$ This property could be of valuable interest to increase intracellular chemotherapy penetration and/or transfect therapeutic DNA into cancer cells. A concomitant administration of targeted chemotherapy with plasma treatment could improve efficacy of chemotherapy and plasma alone.

\section{CONCLUSIONS}

In conclusion, our study demonstrates a marked antitumor effect of plasma treatment in U87 glioma xenografts with a significant decrease of tumor volume at the end of treatment and an increase of mouse life span of $60 \%$, thus confirming our previous data. These results, obtained in a radio and chemoresistant model, are very promising and highlight the potential of plasma treatment as an anticancer treatment with little or no toxic side effects. However, many questions remain unanswered, and further studies are required to elucidate mechanisms involved in this decrease of tumor volume; in particular, by apoptosis and cell cycle analysis. Moreover, studies to identify the main components of plasma implicated in the cytotoxic effect will allow us to develop plasma types with a greater efficacy. Indeed, our lab developed a pulsed plasma gun delivering 
a very fast moving plasma bullet in a $200 \mu \mathrm{m}$ inner diameter flexible dielectric capillary a few tens of centimeters long. ${ }^{39}$ In the future, this plasma gun could be used for in situ cancer treatment by endoscopic application.

\section{ACKNOWLEDGMENTS}

This work was supported by Region Centre through the APR program "PlasMed." The authors thank the PlasMed medical advisory board of University Hospital in Tours and Regional Hospital in Orleans. M.V. is supported by a Germitec doctoral fellowship.

\section{REFERENCES}

1. Ferlay J, Autier P, Boniol M, Heanue M, Colombet M, Boyle P. Estimates of the cancer incidence and mortality in Europe in 2006. Ann Oncol. 2007;18:581-92.

2. Furnari FB, Fenton T, Bachoo RM, Mukasa A, Stommel JM, Stegh A, Hahn WC, Ligon KL, Louis DN, Brennan C, Chin L, DePinho RA, Cavenee WK. Malignant astrocytic glioma: genetics, biology, and paths to treatment. Genes Dev. 2007;21:2683-710.

3. Ohgaki H, Kleihues P. Epidemiology and etiology of gliomas. Acta Neuropathol. 2005;109:93-108.

4. Favia P. Special Issue: Biomedical Applications of Plasma Processes. Plasma Process Polym. 2006;3:383-561

5. Laroussi M. Non thermal decontamination of biological media by atmospheric-pressure plasmas: review, analysis, and prospects. IEEE Trans Plasma Sci. 2002;30:1409-15.

6. Weltmann KD, Brandenburg R, von Woedtke T, Ehlbeck J, Foest R, Stieber M, Kindel E. Antimicrobial treatment of heat sensitive products by miniaturized atmospheric pressure plasma jets (APPJs). J Phys D. 2008;41:194008-194014.

7. Moisan M, Barbeau J, Moreau S, Pelletier J, Tabrizian M, Yahia LH. Low-temperature sterilization using gas plasmas: a review of the experiments and an analysis of the inactivation mechanisms. Int J Pharm. 2001;226:1-21.

8. Fridman G, Peddinghaus M, Ayan H, Fridman A, Balasubramanian M, Gutsol A, Brooks A, Friedman G. Blood coagulation and living tissue sterilization by floating-electrode dielectric barrier discharge in air. Plasma Chem Plasma Process. 2006;26:425-42.

9. Kieft IE, Broers JLV, Caubet-Hilloutou V, Slaaf DW, Ramaekers FCS, Stoffels E. Electric discharge plasmas influence attachment of cultured $\mathrm{CHO}$ k1 cells. Bioelectromagnetics. 2004;25:362-8.

10. Kieft IE, Kurdi M, Stoffels E, editors. Reattachment and apoptosis after plasma-needle treatment of cultured cells. 4th International Symposium on Non thermal Medical/Biological Treatments Using Electromagnetic Fields and Ionized Gases; 2005 May; Portland, OR: IEEE-Inst Electrical Electronics Engineers Inc.; 2005.

11. Stoffels E, Kieft IE, Sladek REJ, van den Bedem LJM, van der Laan EP, Steinbuch M, editors. Plasma needle for in vivo medical treatment: recent developments and perspectives. European Summer School on Low Temperature Plasma Physics; 2004 Sep 26-Oct 8; Bad Honnef, Germany: IOP Publishing Ltd.; 2006;15:169-180. 
12. Yonson S, Coulombe S, Leveille V, Leask RL. Cell treatment and surface functionalization using a miniature atmospheric pressure glow discharge plasma torch. J Phys D. 2006;39:3508-13.

13. Shashurin A, Keidar M, Bronnikov S, Jurjus RA, Stepp MA. Living tissue under treatment of cold plasma atmospheric jet. Appl Phys Lett. 2008;93:181501-181503.

14. Fridman G, Shereshevsky A, Jost MM, Brooks AD, Fridman A, Gutsol A, Vasilets V, Friedman G. Floating electrode dielectric barrier discharge plasma in air promoting apoptotic behavior in melanoma skin cancer cell lines. Plasma Chem Plasma Process. 2007;27:163-76.

15. Kim GC, Kim GJ, Park SR, Jeon SM, Seo HJ, Iza F, Lee JK. Air plasma coupled with antibody-conjugated nanoparticles: a new weapon against cancer. J Phys D. 2009;42:032005032010 .

16. Stoffels E, Sakiyama Y, Graves DB. Cold atmospheric plasma: charged species and their interactions with cells and tissues. IEEE Trans Plasma Sci. 2008;36:1441-57.

17. Vandamme M, Robert E, Pesnel S, Barbosa E, Dozias S, Sobilo J, Lerondel S, Le Pape A, Pouvesle J-M. Antitumor effect of plasma treatment on U87 glioma xenografts: preliminary results. Plasma Process Polym. 2010;7 :264-273.

18. Euhus DM, Hudd C, Laregina M, Johnson FE. Tumor measurement in the nude-mouse. J Surg Oncol. 1986;31:229-34.

19. Tomayko MM, Reynolds CP. Determination of subcutaneous tumor size in athymic (nude) mice. Cancer Chemother Pharmacol. 1989;24:148-54.

20. Jenkins DE, Oei Y, Hornig YS, Yu SF, Dusich J, Purchio T, Contag PR. Bioluminescent imaging (BLI) to improve and refine traditional murine models of tumor growth and metastasis. Clin Exp Metastasis. 2003;20:733-44.

21. Lu X, Laroussi M. Dynamics of an atmospheric pressure plasma plume generated by submicrosecond voltage pulses. J Appl Phys. 2006;100:063302-063308.

22. Ayan H, Staack D, Fridman G, Gutsol A, Mukhin Y, Starikovskii A, Fridman A, Friedman G. Application of nanosecond-pulsed dielectric barrier discharge for biomedical treatment of topographically non-uniform surfaces. J Phys D: Appl Phys. 2009;42:125002-125007.

23. Suit HD, Zietman A, Tomkinson K, Ramsay J, Gerweck L, Sedlacek R. Radiation response of xenografts of a human squamous cell carcinoma and a glioblastoma multiforme: a progress report. Int J Radiat Oncol Biol Phys. 1990;18:365-73.

24. Taghian A, DuBois W, Budach W, Baumann M, Freeman J, Suit H. In vivo radiation sensitivity of glioblastoma multiforme. Int J Radiat Oncol Biol Phys. 1995;32:99-104.

25. Baumann M, DuBois W, Pu A, Freeman J, Suit HD. Response of xenografts of human malignant gliomas and squamous cell carcinomas to fractionated irradiation. Int J Radiat Oncol Biol Phys. 1992;23:803-9.

26. Labussiere M, Aarnink A, Pinel S, Taillandier L, Escanye JM, Barberi-Heyob M, BernierChastagner V, Plenat F, Chastagner P. Interest of liposomal doxorubicin as a radiosensitizer in malignant glioma xenografts. Anticancer Drugs. 2008;19:991-8.

27. Hildebrandt B, Wust P, Ahlers O, Dieing A, Sreenivasa G, Kerner T, Felix R, Riess H. The cellular and molecular basis of hyperthermia. Crit Rev Oncol/Hematol. 2002;43:33-56.

28. Palmer RMJ, Ferrige AG, Moncada S. Nitric-oxide release accounts for the biological-activity of endothelium-derived relaxing factor. Nature. 1987;327:524-6. 
29. Tucker AT, Pearson RM, Cooke ED, Benjamin N. Effect of nitric-oxide-generating system on microcirculatory blood flow in skin of patients with severe Raynaud's syndrome: a randomised trial. Lancet. 1999;354:1670-5.

30. Song CW, Shakil A, Griffin RJ, Okajima K. Improvement of tumor oxygenation status by mild temperature hyperthermia alone or in combination with carbogen. Semin Oncol. 1997;24:626-32.

31. Batista LFZ, Roos WP, Kaina B, Menck CFM. p53 mutant human glioma cells are sensitive to UV-C-induced apoptosis due to impaired cyclobutane pyrimidine dimer removal. Mol Cancer Res. 2009;7:237-46.

32. Anderson RR, Parrish JA. The optics of human-skin. J Invest Dermatol. 1981;77:13-9.

33. Kirson ED, Dbaly V, Tovarys F, Vymazal J, Soustiel JF, Itzhaki A, Mordechovich D, Steinberg-Shapira S, Gurvich Z, Schneiderman R, Wasserman Y, Salzberg M, Ryffel B, Goldsher D, Dekel E, Palti Y. Alternating electric fields arrest cell proliferation in animal tumor models and human brain tumors. Proc Natl Acad Sci U S A. 2007;104:10152-7.

34. Kirson ED, Gurvich Z, Schneiderman R, Dekel E, Itzhaki A, Wasserman Y, Schatzberger R, Palti Y. Disruption of cancer cell replication by alternating electric fields. Cancer Res. 2004;64:3288-95.

35. Moeller BJ, Richardson RA, Dewhirst MW. Hypoxia and radiotherapy: opportunities for improved outcomes in cancer treatment. Cancer Metastasis Rev. 2007;26:241-8.

36. Seiwert TY, Salama JK, Vokes EE. The concurrent chemoradiation paradigm-general principles. Nat Clin Pract Oncol. 2007;4:86-100.

37. Ogawa Y, Morikawa N, Ohkubo-Suzuki A, Miyoshi S, Arakawa H, Kita Y, Nishimura S. An epoch-making application of discharge plasma phenomenon to gene-transfer. Biotechnol Bioeng. 2005;92:865-70.

38. Sakai Y, Khajoee V, Ogawa Y, Kusuhara K, Katayama Y, Hara T. A novel transfection method for mammalian cells using gas plasma. J Biotechnol. 2006;121:299-308.

39. Robert E, Barbosa E, Dozias S, Vandamme M, Cachoncinlle C, Viladrosa R, Pouvesle J-M. Experimental study of a nanosecond plasma gun. Plasma Process Polym. 2009;6:795-802. 
